\title{
Birth weight for gestational age norms for a large cohort of infants born to HIV-negative women in Botswana compared with norms for U.S.-born black infants
}

Lynn T Matthews ${ }^{1,2^{*}}$, Heather J Ribaudo ${ }^{3}$, Natasha K Parekh ${ }^{4}$, Jennifer Y Chen ${ }^{5}$, Kelebogile Binda ${ }^{6}$, Anthony Ogwu ${ }^{6}$, Joseph Makhema ${ }^{6}$, Sajini Souda ${ }^{6}$, Shahin Lockman ${ }^{7}$, Max Essex $^{8}$ and Roger L Shapiro ${ }^{1}$

\begin{abstract}
Background: Standard values for birth weight by gestational age are not available for sub-Saharan Africa, but are needed to evaluate incidence and risk factors for intrauterine growth retardation in settings where HIV, antiretrovirals, and other in utero exposures may impact birth outcomes.

Methods: Birth weight data were collected from six hospitals in Botswana. Infants born to HIV-negative women between 26-44 weeks gestation were analyzed to construct birth weight for gestational age charts. These data were compared with published norms for black infants in the United States.

Results: During a 29 month period from 2007-2010, birth records were reviewed in real-time from 6 hospitals and clinics in Botswana. Of these, 11,753 live infants born to HIV-negative women were included in the analysis. The median gestational age at birth was 39 weeks ( $1^{\text {st }}$ quartile $38,3^{\text {rd }}$ quartile 40 weeks), and the median birth weight was 3100 grams ( $1^{\text {st }}$ quartile $2800,3^{\text {rd }}$ quartile 3400 grams). We constructed estimated percentile curves for birth weight by gestational age which demonstrate increasing slope during the third trimester and leveling off beyond 40 weeks. Compared with black infants in the United States, Botswana-born infants had lower median birth weight for gestational age from weeks 37 through $42(p<.02)$.

Conclusions: We present birth weight for gestational age norms for Botswana, which are lower at term than norms for black infants in the United States. These findings suggest the importance of regional birth weight norms to identify and define risk factors for higher risk births. These data serve as a reference for Botswana, may apply to southern Africa, and may help to identify infants at risk for perinatal complications and inform comparisons among infants exposed to HIV and antiretrovirals in utero.
\end{abstract}

\section{Background}

Each year over 4 million infants die in the first four weeks of life (the neonatal period). Ninety-eight percent of neonatal deaths take place in the developing world, and the highest risk is in Africa, where an average of 41 neonatal deaths occur per 1000 live births [1]. Botswana, a middle-income country in southern Africa, has a welldeveloped medical infrastructure where $97 \%$ of women

\footnotetext{
* Correspondence: Itmatthe@bidmc.harvard.edu

${ }^{1}$ Beth Israel Deaconess Medical Center, Division of Infectious Disease, 110 Francis Street, Lowry Medical Office Building - Suite GB, Boston, MA 02115, USA

Full list of author information is available at the end of the article
}

access antenatal care, $94 \%$ of births are overseen by a skilled attendant, and $80 \%$ of women access hospitalbased obstetrical care for deliveries [1]. However, neonatal mortality in Botswana remains high, estimated at 46/ 1000 live births in 2004 [1].

Botswana is in the midst of a generalized HIV epidemic, and up to a third of infants are born to HIVinfected women [2]. HIV infection is associated with adverse birth outcomes and early infant mortality [3-12]. Although the use of combination antiretroviral drugs for maternal health and for the prevention of mother-tochild HIV transmission is likely to reduce overall infant

\section{() Biomed Central}


mortality by decreasing HIV infection among infants [13-15], the use of antiretrovirals (ARVs) has also been associated with lower birth weights [16-19]. A better understanding of the links between HIV, ARVs, and birth outcomes is required, particularly in resource-limited settings where obstetric and pediatric resources are often limited [17].

Low birth weight infants ( $<2500$ grams) are at risk for early death $[20,21]$. Weight by gestational age is an important outcome that controls for effects of prematurity and is interpreted as a proxy for intrauterine growth restriction [20,22-25]. Small for gestational age infants (birth weight $<10^{\text {th }}$ percentile for gestational age) are at risk for complications such as peripartum asphyxia, birth trauma, hypoglycemia, impaired neurological development and perinatal mortality [26-30]. Because birth weights may vary regionally, the creation of specific norms for birth weight by gestational age in Botswana may be an important step towards identifying infants at risk for early death $[27,31,32]$.

In this report we describe birth weight for gestational age for a large cohort of infants born to HIV-negative women in 6 hospitals in Botswana. Botswana is well-suited for development of these norms as the majority of births occur in hospital settings where information on birth weight, gestational age, and maternal HIV status is available. We compare these data with U.S. birth weight data for black infants with the goal of providing reference data for assessing birth weight for gestational age for both HIV-exposed and unexposed infants in Botswana.

\section{Methods \\ Study population}

Birth weight and gestational age were recorded for live births at six government facilities over a 29 month period from October 19, 2007 to March 16, 2010. Surveillance started at Princess Marina Hospital in Gaborone, the largest hospital in Botswana. Surveillance began in 2008 at Scottish Livingstone Hospital in Molepole and at Broadhurst and Old Naledi clinics in Gaborone. In 2009, surveillance expanded to Deborah Reteif Hospital in the village of Mochudi in southern Botswana, Ghanzi Primary Hospital in western Botswana, Letsolathebe Hospital in Maun in northwestern Botswana, and to Nyangabgwe Hospital in Francistown, the largest city in northern Botswana.

Princess Marina Hospital is the largest hospital in Botswana and serves as a tertiary referral center for the southern part of the country; the Broadhurst and Old Naledi clinics are smaller clinics in Gaborone. Scottish Livingstone Hospital and Debora Reteif hospitals are district-level referral centers. The hospitals in Francistown and Ghanzi serve as referral centers for northern and western Botswana, respectively.
This study was approved by the Office of Human Research Administration at the Harvard School of Public Health, by the Health Research Development Committee in Botswana, and by all participating hospitals.

\section{Outcomes and Exclusions}

Birth weights were abstracted (JYC, NP) from obstetric records and delivery registries completed by maternity nurses. Extracted data included birth weight, infant gender, delivery date, gestational age, maternal age, and documented HIV status. In the event of multiple gestations, the outcome of the first-born infant was recorded. Clinical staff assessed and recorded gestational age at delivery using last normal menstrual period and fundal height assessment. Gestational ages are not confirmed by ultrasound in Botswana's public hospitals.

Our analyses included live births to HIV-negative mothers between 26 and 44 weeks of gestation with no known congenital abnormality. Cases for which a live birth could not be confirmed (including still-births and those of unknown status) and births to women of positive or unknown HIV-status were excluded. Births with documented congenital abnormalities were also excluded. Because of concerns regarding data accuracy, infants with recorded birth weight less than 450 grams or greater than 6500 grams across all gestational ages and those with a recorded birth-weight that was $20 \%$ lower than the first percentile or $20 \%$ higher than the ninety-ninth percentile of published distributional norms of black infants born in the U.S. were also excluded [25]. This U.S. reference represents a large, comprehensive dataset and detailed data were available in the public domain. Outlier weights identified in the prior step were reviewed by four pediatricians. Values that the majority judged to be reasonable to exclude or include were treated accordingly [32]. (See Figure 1.)

\section{Statistical Methods}

Smoothed birth weight percentiles for gestational ages 26-44 weeks were estimated using quantile regression analyses with natural cubic B-spline with knots at weeks $24,26,28,38,40,44$ [33-35]. Knot selection was determined based on visual inspection of the fit and distributional shape compared to published birth weight data from other settings [31,36-38]. Estimated percentile curves at gestational ages less than 30 or greater than 43 weeks are not plotted but the data for these extremes of gestational age were retained in the analysis for modeling purposes. Use of this broader data range in modeling provides a more realistic representation of growth profiles over time. However, the small sample size and, thus, estimate precision limits the generalizability at these data extremes. All summary data are presented in Table 1. 


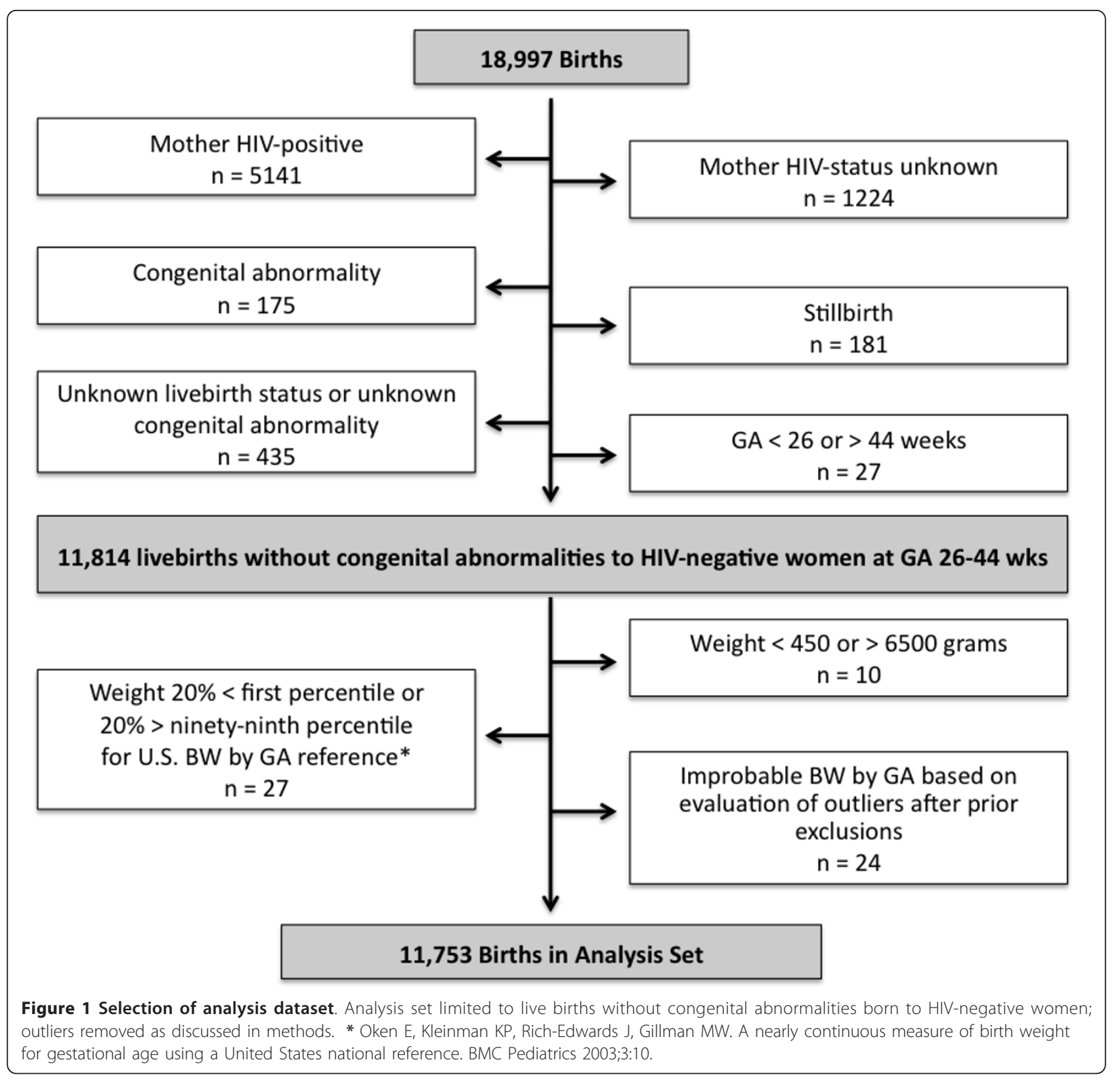

Wilcoxon rank sum test, stratified by gestational age, was used to compare birthweight for gestational age among girls and boys. Birthweight at each gestational age was compared with the U.S. median weight for that gestational age using Wilcoxon signed rank test. All analyses were performed in SAS 9.2 for UNIX.

\section{Results}

The initial dataset (18,997 births) was first restricted to 11,814 live births, born to HIV-negative women, without congenital abnormality, between 26 and 44 weeks of gestation. An HIV status was recorded for $94 \%$ of mothers in the initial dataset. Of the excluded outcomes, 5,141 (72\%) were births to HIV-positive women and 1,224 were to women of unknown HIV status. Among the excluded births to HIV-negative women, 181 were stillbirths, 175 had a congenital abnormality, 435 had unrecorded birth or congenital abnormality outcome, and 27 had gestational age less than 26 or greater than 44 weeks. In addition, sixty-one outliers were removed as described in the methods, leaving a total of 11,753 in the analysis dataset (Figure 1). For the final analysis dataset, $8,009(68 \%)$ of captured births were from Princess Marina Hospital, 1,563 (13\%) from Scottish Livingstone Hospital, 763 (8\%) from Nyangabgwe (Francistown), while $<5 \%$ (700 or fewer) came from each of the remaining sites. 
Table 1 Distribution of birth weights for gestational age for babies born to HIV-negative women in Botswana compared with median for babies born to black women in the U.S.

\begin{tabular}{|c|c|c|c|c|c|c|c|c|c|}
\hline $\begin{array}{l}\text { Gestational Age } \\
\text { (weeks) }\end{array}$ & $N$ & $\begin{array}{c}\text { Minimum } \\
\text { (grams) }\end{array}$ & $\begin{array}{c}\text { Lower Quartile } \\
\text { (grams) }\end{array}$ & $\begin{array}{l}\text { Median } \\
\text { (grams) }\end{array}$ & $\begin{array}{l}\text { Upper Quartile } \\
\text { (grams) }\end{array}$ & $\begin{array}{c}\text { Maximum } \\
\text { (grams) }\end{array}$ & $\begin{array}{l}\text { U.S. median * } \\
\text { (grams) }\end{array}$ & $\begin{array}{c}\Delta \text { Median } \\
\text { (Botswana - U.S.) }\end{array}$ & $\begin{array}{c}\text { p- } \\
\text { value }^{\dagger}\end{array}$ \\
\hline 26 & 9 & 700 & 880 & 930 & 1230 & 1680 & 857 & 73 & .051 \\
\hline 27 & 20 & 670 & 1013 & 1116 & 1610 & 2310 & 977 & 139 & .004 \\
\hline 28 & 29 & 790 & 1120 & 1260 & 1740 & 2700 & 1120 & 140 & .003 \\
\hline 29 & 54 & 750 & 1200 & 1375 & 1725 & 2950 & 1304 & 71 & .015 \\
\hline 30 & 62 & 860 & 1390 & 1660 & 2180 & 2990 & 1525 & 135 & .002 \\
\hline 31 & 71 & 810 & 1535 & 1815 & 2630 & 3300 & 1804 & 11 & .032 \\
\hline 32 & 119 & 800 & 1680 & 2085 & 2730 & 3440 & 2084 & 0.6 & .099 \\
\hline 33 & 162 & 1170 & 2055 & 2410 & 2790 & 3790 & 2358 & 52 & .370 \\
\hline 34 & 268 & 1380 & 2100 & 2510 & 2928 & 3850 & 2571 & -61 & .095 \\
\hline 35 & 394 & 1180 & 2320 & 2700 & 3060 & 4200 & 2733 & -33 & .172 \\
\hline 36 & 687 & 1470 & 2560 & 2850 & 3115 & 4335 & 2870 & -20 & .164 \\
\hline 37 & 1056 & 1790 & 2690 & 2960 & 3240 & 4680 & 3014 & -53 & $<.001$ \\
\hline 38 & 1758 & 1900 & 2820 & 3060 & 3330 & 4550 & 3158 & -98 & $<.001$ \\
\hline 39 & 2340 & 1890 & 2890 & 3130 & 3405 & 5150 & 3277 & -147 & $<.001$ \\
\hline 40 & 2482 & 1960 & 2970 & 3220 & 3500 & 4920 & 3356 & -135 & $<.001$ \\
\hline 41 & 1357 & 1980 & 3000 & 3290 & 3600 & 5000 & 3399 & -109 & $<.001$ \\
\hline 42 & 746 & 2000 & 3000 & 3300 & 3610 & 5080 & 3346 & -45 & .016 \\
\hline 43 & 125 & 2300 & 3000 & 3280 & 3540 & 4405 & 3316 & -35 & .492 \\
\hline 44 & 14 & 2680 & 3100 & 3345 & 3700 & 4785 & 3328 & 16 & .583 \\
\hline
\end{tabular}

* Oken E, Kleinman KP, Rich-Edwards J, Gillman MW. A nearly continuous measure of birth weight for gestational age using a United States national reference. BMC Pediatrics 2003;3:10.

${ }^{+}$Wilcoxon signed rank test.

Data for weight by gestational age ranging from 26 to 44 weeks are shown in Table 1. The number of infants at each gestational age ranged from 9 at 26 weeks to 2482 at 40 weeks. Among all infants, the median gestational age at the time of birth was 39 weeks, and the median birth weight was 3100 (IQR 2800-3400) grams. Boys were generally heavier than girls at each gestational age with a median of 3160 (IQR 2850, 3480) grams compared with 3030 (IQR 2750, 3325) grams ( $<$ < .0001 ), respectively.

Figure 2 shows estimated percentile curves from 30-43 weeks gestation for 11,627 males and females combined from the final analysis dataset. These curves are similar to prior birth weight for gestational age data with increasing slope during the third trimester and leveling off beyond 40 weeks $[25,39]$.

Figure 3 shows percentile curves constructed from the Botswana dataset superimposed with curves for U.S.born black infants [25]. Observation of the curves and the data (Table 1) suggest that Botswana-born infants tended to be larger than U.S.-born infants after shorter gestation $(<34$ weeks) and smaller than U.S. born infants after longer gestation ( $\geq 34$ weeks). These observed differences are significant at weeks 27-31 and weeks 37-42 ( $\mathrm{p} \leq .04$, Table 1$)$.

Table 2 shows weight by percentile for gestational age. The $10^{\text {th }}$ percentile for U.S. data is shown for comparison. The $10^{\text {th }}$ percentile (the standard cut-off for small for gestational age) values are observed to be higher for pre-term babies in Botswana than for preterm U.S.-born babies, but to be similar at and beyond term.

\section{Discussion}

This report describes infant birth weight for gestational age for the largest cohort of infants born to HIV-negative women reported from southern Africa. These data may serve as a reference for identifying infants at risk for early complications and for assessing potential risk factors for adverse infant outcomes, including maternal HIV infection and exposure to antiretrovirals in utero.

These data may be representative for births in Botswana. Based on annual and estimated birth rates for Botswana, there were 114,620 births over the 29 months of surveillance [40]. The initial data set included 18,997 or about $17 \%$ of recorded births for the period. In addition, $10.8 \%$ of infants in this dataset meet the definition for low birth weight which is consistent with national statistics reporting 10\% incidence [20]. Although Princess Marina Hospital, the largest hospital in the country, contributed the majority of the data, the additional sample sites were located throughout the country and included primary sites as well as regional and national referral centers. Because an estimated $80 \%$ of births 

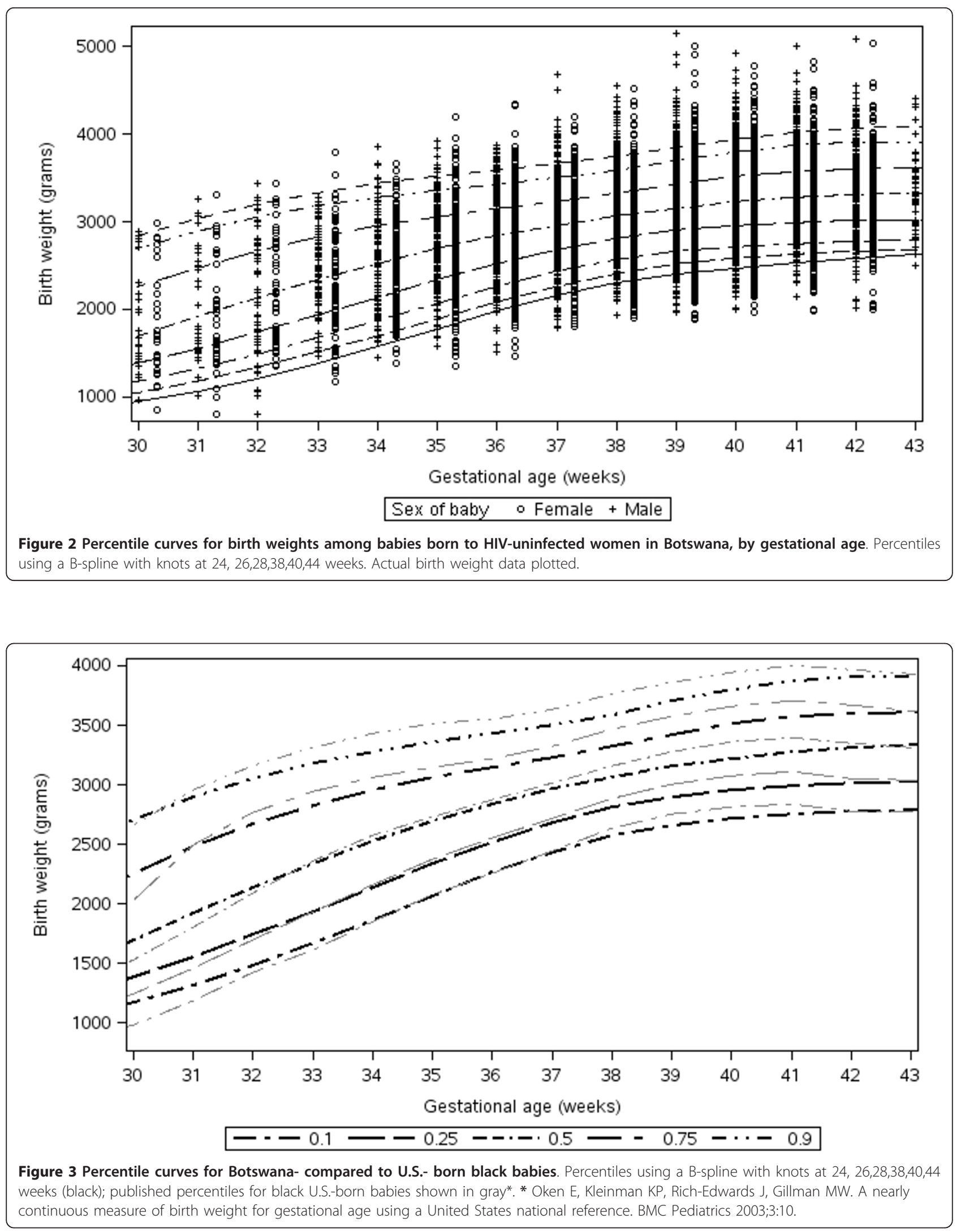
Table 2 Estimated birth weight percentile by gestational age for babies born to HIV-negative women in Botswana

\begin{tabular}{ccccccccccc}
\hline & \multicolumn{7}{c}{ Estimated birth weight percentile (grams) by gestational age } \\
\hline Gestation age (weeks) & $\mathbf{N}$ & $\mathbf{3}^{\text {rd }}$ & $\mathbf{5}^{\text {th }}$ & $\mathbf{1 0}^{\text {th }}$ & $\mathbf{2 5}^{\text {th }}$ & $\mathbf{5 0}^{\text {th }}$ & $\mathbf{7 5}^{\text {th }}$ & $\mathbf{9 0}^{\text {th }}$ & $\mathbf{9 5}^{\text {th }}$ & $\mathbf{1 0}^{\text {th }} \mathbf{U . S .}^{*}$ \\
\hline 30 & 62 & 946 & 1042 & $\mathbf{1 1 7 0}$ & 1380 & 1693 & 2255 & 2699 & 2840 & $\mathbf{9 8 0}$ \\
31 & 71 & 1067 & 1179 & $\mathbf{1 3 1 8}$ & 1553 & 1915 & 2475 & 2895 & 3038 & $\mathbf{1 1 8 8}$ \\
32 & 119 & 1214 & 1336 & $\mathbf{1 4 8 5}$ & 1740 & 2130 & 2664 & 3054 & 3200 & $\mathbf{1 4 1 9}$ \\
33 & 162 & 1384 & 1509 & $\mathbf{1 6 7 0}$ & 1936 & 2333 & 2822 & 3179 & 3330 & $\mathbf{1 6 1 6}$ \\
34 & 268 & 1574 & 1697 & $\mathbf{1 8 6 6}$ & 2135 & 2520 & 2950 & 3277 & 3433 & $\mathbf{1 8 4 9}$ \\
35 & 394 & 1777 & 1891 & $\mathbf{2 0 6 7}$ & 2332 & 2688 & 3055 & 3356 & 3517 & $\mathbf{2 0 7 0}$ \\
36 & 687 & 1979 & 2082 & $\mathbf{2 2 6 0}$ & 2517 & 2834 & 3146 & 3427 & 3590 & $\mathbf{2 2 4 8}$ \\
37 & 1056 & 2165 & 2258 & $\mathbf{2 4 3 3}$ & 2680 & 2960 & 3230 & 3500 & 3663 & $\mathbf{2 4 3 9}$ \\
38 & 1758 & 2313 & 2405 & $\mathbf{2 5 7 0}$ & 2810 & 3065 & 3320 & 3588 & 3747 & $\mathbf{2 6 3 2}$ \\
39 & 2340 & 2409 & 2510 & $\mathbf{2 6 6 0}$ & 2900 & 3152 & 3420 & 3697 & 3848 & $\mathbf{2 7 5 0}$ \\
40 & 2482 & 2471 & 2580 & $\mathbf{2 7 1 4}$ & 2957 & 3220 & 3511 & 3800 & 3945 & $\mathbf{2 8 1 4}$ \\
41 & 1357 & 2525 & 2626 & $\mathbf{2 7 5 0}$ & 2992 & 3270 & 3570 & 3867 & 4015 & $\mathbf{2 8 3 6}$ \\
42 & 746 & 2577 & 2654 & $\mathbf{2 7 7 3}$ & 3012 & 3305 & 3600 & 3900 & 4060 & $\mathbf{2 7 7 9}$ \\
43 & 125 & 2629 & 2670 & $\mathbf{2 7 8 8}$ & 3021 & 3330 & 3610 & 3910 & 4088 & $\mathbf{2 7 7 0}$ \\
\hline
\end{tabular}

* $10^{\text {th }}$ percentile for U.S.-born black infants. Oken E, Kleinman KP, Rich-Edwards J, Gillman MW. A nearly continuous measure of birth weight for gestational age using a United States national reference. BMC Pediatrics 2003;3:10

occur in healthcare facilities, institutional deliveries should approximate population norms. Those $20 \%$ of births that were not captured may represent a combination of rural, poorer women who cannot readily access healthcare as well as more affluent women who access private clinics.

Birth weight monitoring is complicated in countries where the majority of births occur outside healthcare facilities. For most developing countries, birth weight data are collected via annual Demographic Health Survey records and birth weight for gestational age is generally unavailable $[20,41]$. Institutional birth weight data from Botswana offer a more reliable representation of population norms compared to many other developing country settings since $80 \%$ of women access hospitalbased obstetrical and neonatal care [1]. Data from hospital-based deliveries in Botswana may therefore be useful to other countries in southern Africa.

The Botswana-born infants had higher average birth weights pre-term (statistically significant at 27-31 weeks) and lower birth weights at term (statistically significant at 37-42 weeks) than U.S.-born infants in the referent dataset. Several studies have explored the potential inaccuracies of gestational age dating by last menstrual period. Dating is often inaccurate due to recall bias, variable menstrual cycles, and misinterpretation of bleeding at the time of embroyo implantation. The summation of these errors results in underestimation of prematurity (thus higher birth weights pre-term) and overestimation of post-dates (thus lower birth weights post-term) [42-46]. Distributions around term tend to be less affected by this variation, in part due to larger sample sizes. Among women in the analysis dataset who had antenatal clinic visit information ( 50\%), 98\% had attended an antenatal clinic at least once, which may increase the reliability of the dating. Both datasets estimated gestation age based on last menstrual period, but it is likely that the larger numbers in the U.S. dataset improved precision. Our sample sizes exceeded 100 between 32-41 weeks and thus we have the most confidence in these numbers. It is also possible that Botswana-born children have lower birth weight at term than U.S.-born black infants due to ethnic and/or racial variability of third trimester birth weight for gestational age $[25,27,32]$ or due to environmental differences.

Because Botswana-born term babies were smaller than U.S.-born babies, the $10^{\text {th }}$ percentile cut-offs were lower. By convention, the $10^{\text {th }}$ percentile is the cut-off to define small for gestational age [47]. Additional research will be required to assess whether infants at highest risk are those below the $10^{\text {th }}$ percentile or if in this setting a larger proportion of infants are at risk for early mortality.

There are several limitations to these data. Reported data were collected from six different hospitals, however $68 \%$ of the data were from Princess Marina Hospital, a tertiary referral site. These women may represent a wealthier urban population, as well as women referred with complicated pregnancies. In addition, these data were not restricted to singleton births, thus potentially skewing the data towards lower birth weights. Third, estimated gestational age may be inaccurate when estimated from last menstrual period [42,45]. We attempted to correct the data by excluding implausible birth weights at each gestational age, and by restricting the dataset to include only infants from 26 to 44 weeks 
gestation. Multiple strategies for exclusion of implausible birth weights have been explored [32,36,39,48-51] and several strategies were applied to these data. The method we employed resulted in the best fit for constructed growth curves. In addition, the comparison dataset was taken from published norms for black infants born in the U.S; however, birth weights by gestational age for black U.S.-born children are lower than for other U.S.-born groups [25,39]. In addition, the reference dataset includes HIV-positive and HIV-negative mothers. Given that the HIV-prevalence for black women in the U.S. is estimated at $1.1 \%$, this is unlikely to significantly impact the data [52]. Finally, we only included data for women who had a known negative HIV status; this limits population-wide applicability, but will facilitate future comparisons of HIV-exposed infants with the norms presented in this dataset. This group will publish the findings for infants born to the HIVpositive women in a separate manuscript [19].

\section{Conclusions}

We present a reference for birth weight for gestational age for a large sample of infants born to HIV-negative women in hospitals in Botswana, and demonstrate lower median term birth weights than reported for black infants born in the United States. These data should prove useful for future research investigating the determinants of neonatal mortality and for assessing the effects of HIV and antiretrovirals on infant birth weight.

\section{List of abbreviations}

HIV: Human immunodeficiency virus; ARVs: antiretrovirals.

\section{Acknowledgements and Disclosures}

Dr. Matthews is supported by a postdoctoral fellowship in infectious diseases from the Burroughs Wellcome Fund and the American Society for Tropical Medicine and Hygiene and by a K23 award (MH095655). Dr. Ribaudo's work was supported by the Harvard University Center for AIDS Research Biostatistical Core (NIH \#Al060354). Dr. Shapiros' work was supported by a grant from the Centers for Disease Control and Prevention (President's Emergency Plan for AIDS Relief).

We would like to thank the patients and hospital staff at the study sites in Botswana. We also acknowledge Drs. Jonathan Litt, Lynn Ramirez, Kathleen Powis and Brian Zanoni for valuable contributions.

\footnotetext{
Author details

${ }^{1}$ Beth Israel Deaconess Medical Center, Division of Infectious Disease, 110 Francis Street, Lowry Medical Office Building - Suite GB, Boston, MA 02115 , USA. ${ }^{2}$ Massachusetts General Hospital, Division of Infectious Disease, Center for Global Health, 100 Cambridge Street, Boston, MA, 02114, USA. ${ }^{3}$ Harvard School of Public Health, 651 Huntington Avenue, FXB Building - Room 509, Boston, MA 02115, USA. ${ }^{4}$ University of Miami, Miller School of Medicine, 1600 NW Tenth Avenue, Miami, FL 33136, USA. ${ }^{5}$ Harvard Medical School, 25 Shattuck Street, Boston, MA 02115, USA. ${ }^{6}$ Botswana Harvard AIDS Institute, Private Bag BO 320, Bontleng, Gaborone, Botswana. 'Brigham and Women's Hospital, Division of Infectious Disease, 75 Francis Street, Boston, MA 02115, USA. ${ }^{8}$ Harvard School of Public Health, Departments of Immunology and Infectious Disease, 651 Huntington Avenue, FXB Building - Room 401, Boston, MA 02115
}

\section{Authors' contributions}

LTM was responsible for analysis, presentation and primary authorship of the work presented here. HR was primarily responsible for conception, design, analysis, interpretation and contributed to writing. NP and JYC acquired the data; KB contributed data collection and analysis. AO, JM, SS, SL, ME were involved in conception and study design. RLS was involved in all phases of the work. All authors reviewed and approved the final manuscript.

\section{Competing interests}

The authors declare that they have no competing interests.

Received: 24 November 2010 Accepted: 16 December 2011 Published: 16 December 2011

\section{References}

1. UNICEF: Botswana country statistics.[http://www.unicef.org/infobycountry/ botswana_statistics.html].

2. UNAIDS, NACA: UNGASS Botswana Country Report 2010: Reporting period 2008-2009.

3. Brocklehurst $P$, French R: The association between maternal HIV infection and perinatal outcome: a systematic review of the literature and metaanalysis. Br J Obstet Gynaecol 1998, 105(8):836-848.

4. Bulterys M, Chao A, Munyemana S, Kurawige JB, Nawrocki P, Habimana P, Kageruka M, Mukantabana S, Mbarutso E, Dushimimana A, et al: Maternal human immunodeficiency virus 1 infection and intrauterine growth: a prospective cohort study in Butare, Rwanda. Pediatr Infect Dis J 1994, 13(2):94-100.

5. Langston C, Lewis DE, Hammill HA, Popek EJ, Kozinetz CA, Kline MW, Hanson IC, Shearer WT: Excess intrauterine fetal demise associated with maternal human immunodeficiency virus infection. J Infect Dis 1995, 172(6): :1451-1460.

6. Leroy V, Ladner J, Nyiraziraje M, De Clerca A, Bazubagira A, Van de Perre P, Karita E, Dabis F: Effect of HIV-1 infection on pregnancy outcome in women in Kigali, Rwanda, 1992-1994. Pregnancy and HIV Study Group. AIDS 1998, 12(6):643-650

7. Rollins NC, Coovadia HM, Bland RM, Coutsoudis A, Bennish ML, Patel D, Newell ML: Pregnancy outcomes in HIV-infected and uninfected women in rural and urban South Africa. J Acquir Immune Defic Syndr 2007, 44(3):321-328.

8. Ryder RW, Temmerman M: The effect of HIV-1 infection during pregnancy and the perinatal period on maternal and child health in Africa. AIDS 1991, 5(Suppl 1):S75-85.

9. Taha TE, Dallabetta GA, Canner JK, Chiphangwi JD, Liomba G, Hoover DR, Miotti PG: The effect of human immunodeficiency virus infection on birthweight, and infant and child mortality in urban Malawi. Int $J$ Epidemiol 1995, 24(5):1022-1029.

10. Temmerman M, Plummer FA, Mirza NB, Ndinya-Achola JO, Wamola IA, Nagelkerke N, Brunham RC, Piot P: Infection with HIV as a risk factor for adverse obstetrical outcome. AIDS 1990, 4(11):1087-1093.

11. Habib NA, Daltveit AK, Bergsjo P, Shao J, Oneko O, Lie RT: Maternal HIV status and pregnancy outcomes in northeastern Tanzania: a registrybased study. BJOG 2008, 115(5):616-624.

12. Habib NA, Dalveit AK, Mlay J, Oneko O, Shao J, Bergsjo P, Lie-Nielsen E, Lie RT: Birthweight and perinatal mortality among singletons and twins in north-eastern Tanzania. Scand J Public Health 2008, 36(7):761-768.

13. Kumwenda NI, Hoover DR, Mofenson LM, Thigpen MC, Kafulafula G, Li Q, Mipando L, Nkanaunena K, Mebrahtu T, Bulterys M, Fowler MG, Taha TE: Extended antiretroviral prophylaxis to reduce breast-milk HIV-1 transmission. N Engl J Med 2008, 359(2):119-129.

14. Shapiro RL, Hughes MD, Ogwu A, Kitch D, Lockman S, Moffat C, Makhema J, Moyo S, Thior I, Mclntosh K, van Widenfelt E, Leidner J, Powis K, Asmelash A, Tumbare E, Zwerski S, Sharma U, Handelsman E, Mburu K, Jayeoba O, Moko E, Souda S, Lubega E, Akhtar M, Wester C, Tuomola R, Snowden W, Martinez-Tristani M, Mazhani L, Essex M: Antiretroviral regimens in pregnancy and breast-feeding in Botswana. $N$ Engl I Med 2010, 362(24):2282-2294

15. De Vincenzi I, Kesho Bora Study Group: Triple antiretroviral compared with zidovudine and single-dose nevirapine prophylaxis during pregnancy and breastfeeding for prevention of mother-to-child transmission of HIV-1 (Kesho Bora study): a randomised controlled trial. Lancet Infect Dis 2011, 11:171-80. 
16. Machado ES, Hofer CB, Costa TT, Nogueira SA, Oliveira RH, Abreu TF, Evangelista LA, Farias IF, Mercadante RT, Garcia MF, Neves RC, Costa VM, Lambert JS: Pregnancy outcome in women infected with HIV-1 receiving combination antiretroviral therapy before versus after conception. Sex Transm Infect 2009, 85(2):82-87.

17. Ekouevi DK, Coffie PA, Becquet R, Tonwe-Gold B, Horo A, Thiebaut R, Leroy $V$, Blanche $S$, Dabis F, Abrams EJ: Antiretroviral therapy in pregnant women with advanced HIV disease and pregnancy outcomes in Abidjan, Cote d'Ivoire. AIDS 2008, 22(14):1815-1820.

18. Townsend CL, Cortina-Borja M, Peckham CS, Tookey PA: Antiretroviral therapy and premature delivery in diagnosed HIV-infected women in the United Kingdom and Ireland. AIDS 2007, 21(8):1019-1026.

19. Chen JY, Ribaudo H, Ogwu a, Lockman S, Syab P, Wester C, Tumbare E, Moffar H, Makhema J, Essex M, Shapiro RL: Risk factors for adverse pregnancy outcomes among HIV-infected and HIV-uninfected women in Gaborone and Molepolole, Botswana. Conference on Retroviruses and Opportunistic Infections Montreal; 2009.

20. United Nations Children's Fund and World Health Organization: Low birthweight: country, regional and global estimates. New York: UNICEF; 2004, 1-31.

21. Bonellie S, Chalmers J, Gray R, Greer I, Jarvis S, Williams C: Centile charts for birthweight for gestational age for Scottish singleton births. BMC Pregnancy Childbirth 2008, 8:5.

22. Briand N, Mandelbrot L, Le Chenadec J, Tubiana R, Teglas JP, Faye A, Dollfus C, Rouzioux C, Blanche S, Warszawski J: No relation between inutero exposure to HAART and intrauterine growth retardation. AIDS 2009, 23(10):1235-1243.

23. Ferdynus C, Quantin C, Abrahamowicz M, Platt R, Burguet A, Sagot P, Binquet C, Gouyon JB: Can birth weight standards based on healthy populations improve the identification of small-for-gestational-age newborns at risk of adverse neonatal outcomes? Pediatrics 2009, 123(2):723-730.

24. W.H.O: Neonatal and perinatal mortality: country, regional and global estimates. Geneva: World Health Organization; 2006, 75.

25. Oken E, Kleinman KP, Rich-Edwards J, Gillman MW: A nearly continuous measure of birth weight for gestational age using a United States national reference. BMC Pediatrics 2003, 3(6):10.

26. de Onis M, Blossner M, Villar J: Levels and patterns of intrauterine growth retardation in developing countries. Eur J Clin Nutr 1998, 52(Suppl 1): S5-15.

27. Fok TF, So HK, Wong E, Ng PC, Chang A, Lau J, Chow CB, Lee WH: Updated gestational age specific birth weight, crown-heel length, and head circumference of Chinese newborns. Arch Dis Child Fetal Neonatal Ed 2003, 88(3):F229-236.

28. Kok JH, den Ouden AL, Verloove-Vanhorick SP, Brand R: Outcome of very preterm small for gestational age infants: the first nine years of life. $\mathrm{Br} J$ Obstet Gynaecol 1998, 105(2):162-168.

29. Malloy $\mathrm{MH}$ : Size for gestational age at birth: impact on risk for sudden infant death and other causes of death, USA 2002. Arch Dis Child Fetal Neonatal Ed 2007, 92(6):F473-478.

30. Wennergren M, Wennergren G, Vilbergsson G: Obstetric characteristics and neonatal performance in a four-year small for gestational age population. Obstet Gynecol 1988, 72(4):615-620.

31. Alshimmiri MM, Al-Saleh EA, Alsaeid K, Hammoud MS, Al-Harmi JA: Birthweight percentiles by gestational age in Kuwait. Arch Gynecol Obstet 2004, 269(2):111-116.

32. Davidson S, Sokolover N, Erlich A, Litwin A, Linder N, Sirota L: New and improved Israeli reference of birth weight, birth length, and head circumference by gestationa age: a hospital-based study. Israeli Medical Association Journal 2008, 10:130-134.

33. Chapter 3. Splines. in Semiparametric regression for the Social Sciences. Edited by: Keele LJ. John Wiley and Sons; 2008:.

34. Wei $Y$, Pere A, Koenker $R$, He X: Quantile regression methods for reference growth charts. Stat Med 2006, 25:1369-1382.

35. Devlin T, Weeks B: Spline functions for logistic regression modeling. Proc Eleventh Annual SAS Users Group International SAS Institute, Inc.; 1986, 646-651.

36. Arbuckle TE, Wilkins R, Sherman GJ: Birth weight percentiles by gestational age in Canada. Obstet Gynecol 1993, 81(1):39-48.
37. Rios JM, Tufino-Olivares E, Reza-Lopez S, Sanin LH, Levario-Carrillo M: Birthweight percentiles by gestational age and gender for children in the North of Mexico. Paediatr Perinat Epidemiol 2008, 22(2):188-194

38. Roberts CL, Lancaster PA: Australian national birthweight percentiles by gestational age. Med J Aust 1999, 170(3):114-118.

39. Alexander GR, Himes JH, Kaufman RB, Mor J, Kogan M: A United States national reference for fetal growth. Obstet Gynecol 1996, 87(2):163-168.

40. United Nations: World Population Prospects: The 2008 Revision. New York: Department of Economic and Social Affairs, Population Division; 2009.

41. Blanc AK, Wardlaw T: Monitoring low birth weight: an evaluation of international estimates and an updated estimation procedure. Bull World Health Organ 2005, 83(3):178-185.

42. Zhang J, Bowes WA Jr: Birth-weight-for-gestational-age patterns by race, sex, and parity in the United States population. Obstet Gynecol 1995, 86(2):200-208

43. Kramer MS, Demissie K, Yang H, Platt RW, Sauve R, Liston R: The contribution of mild and moderate preterm birth to infant mortality. Fetal and Infant Health Study Group of the Canadian Perinatal Surveillance System. JAMA 2000, 284(7):843-849.

44. McLean FH, Boyd ME, Usher RH, Kramer MS: Postterm infants: too big or too small? Am J Obstet Gynecol 1991, 164(2):619-624.

45. Wilcox AJ, Skjaerven R: Birth weight and perinatal mortality: the effect of gestational age. Am J Public Health 1992, 82(3):378-382.

46. Kramer MS, McLean FH, Boyd ME, Usher RH: The validity of gestational age estimation by menstrual dating in term, preterm, and postterm gestations. JAMA 1988, 260(22):3306-3308.

47. Wilcox AJ: On the importance-and the unimportance-of birthweight. Int J Epidemiol 2001, 30(6):1233-1241.

48. Skjaerven R, Gjessing HK, Bakketeig LS: Birthweight by gestational age in Norway. Acta Obstet Gynecol Scand 2000, 79(6):440-449.

49. Kallen B: A birth weight for gestational age standard based on data in the Swedish Medical Birth Registry, 1985-1989. Eur J Epidemiol 1995, 11(5):601-606.

50. Joseph KS, Kramer MS, Allen AC, Mery LS, Platt RW, Wen SW: Implausible birth weight for gestational age. Am J Epidemiol 2001, 153(2):110-113.

51. Platt RW, Abrahamowicz M, Kramer MS, Joseph KS, Mery L, Blondel B, Breart $G$, Wen SW: Detecting and eliminating erroneous gestational ages: a normal mixture model. Stat Med 2001, 20(23):3491-3503.

52. HIV prevalence estimates-United States, 2006. MMWR Morb Mortal Wkly Rep 2008, 57(39):1073-1076.

Pre-publication history

The pre-publication history for this paper can be accessed here: http://www.biomedcentral.com/1471-2431/11/115/prepub

doi:10.1186/1471-2431-11-115

Cite this article as: Matthews et al:: Birth weight for gestational age norms for a large cohort of infants born to HIV-negative women in Botswana compared with norms for U.S.-born black infants. BMC Pediatrics 2011 11:115.

\section{Submit your next manuscript to BioMed Central and take full advantage of:}

- Convenient online submission

- Thorough peer review

- No space constraints or color figure charges

- Immediate publication on acceptance

- Inclusion in PubMed, CAS, Scopus and Google Scholar

- Research which is freely available for redistribution

Submit your manuscript at www.biomedcentral.com/submit
C Biomed Central 